\title{
Correction to: Current Approaches in the Management of Hepatic Adenomas
}

\author{
Diamantis I. Tsilimigras ${ }^{1}$ - Amir A. Rahnemai-Azar ${ }^{2} \cdot$ Ioannis Ntanasis-Stathopoulos ${ }^{3} \cdot$ Maria Gavriatopoulou $^{3}$. \\ Demetrios Moris ${ }^{4}$ - Eleftherios Spartalis ${ }^{1} \cdot$ Jordan M. Cloyd ${ }^{4}$. Sharon M. Weber ${ }^{2} \cdot$ Timothy M. Pawlik $^{4,5}$
}

Published online: 10 October 2019

(C) 2019 The Society for Surgery of the Alimentary Tract

\section{Correction to: J Gastrointest Surg https://doi.org/10.1007/s11605-018-3917-4}

The following reference in this paper refers to a paper that has been since retracted.

70. Zhao C, Pei SL, Cucchetti A, Tong TJ, Ma YL, Zhong $\mathrm{JH}$, et al. Systematic review: benefits and harms of transarterial embolisation for treating hepatocellular adenoma. Aliment Pharmacol Ther. 2017.

Publisher's Note Springer Nature remains neutral with regard to jurisdictional claims in published maps and institutional affiliations.

The online version of the original article can be found at https://oi.org/ 10.1007/s11605-018-3917-4

Timothy M. Pawlik

Tim.Pawlik@osumc.edu

1 Laboratory of Experimental Surgery and Surgical Research, School of Medicine, National and Kapodistrian University of Athens, Athens, Greece

2 Department of Surgery, Division of Surgical Oncology, University of Wisconsin Hospital, Madison, WI, USA

3 Department of Clinical Therapeutics, School of Medicine, National and Kapodistrian University of Athens, Alexandra General Hospital, Athens, Greece

4 Department of Surgery, Division of Surgical Oncology, The Ohio State University Wexner Medical Center and James Cancer Hospital and Solove Research Institute, Columbus, OH, USA

5 Department of Surgery, The Urban Meyer III and Shelley Meyer Chair for Cancer Research, Oncology, Health Services Management and Policy, The Ohio State University, Wexner Medical Center, 395 W. 12th Ave., Suite 670, Columbus, OH, USA 